\title{
EL PARTIDO CONSERVADOR FRENTE A LA CRISIS CONSTITUCIONAL DE 1925
}

\author{
THE CONSERVATIVE PARTY AGAINST THE CONSTITUTIONAL \\ CRISIS OF 1925
}

\section{ENRIQUe Brahm García*}

\begin{abstract}
RESUMEN: De la revisión, en lo fundamental, de la prensa de la época, se desprende que en medio del clima revolucionario que vivía Chile en 1925, los conservadores vieron cuestionado de modo tan radical su visión del mundo, que adoptaron una firme posición defensiva del antiguo orden (régimen parlamentario); sin perjuicio de que en su seno surgieron también posiciones divergentes. Había quienes querían democratizar el sistema, otros que se consagraran derechos sociales y algunos defendían el corporativismo.
\end{abstract}

Palabras clave: Parlamentarismo, presidencialismo, asamblea constituyente, plebiscito.

ABSTRACT: From the revision, in essence, of the press of that time, it appears that in the middle of the revolutionary climate that Chile was living in 1925, conservatives saw so radically questioned their vision of the world, that they adopted a firm defensive position of the old order (parliamentary system); notwhitstanding that within it arose also divergent positions. There were those who wanted to democratize the system, others that social rights were enshrined and a few defended the corporatism.

Key words: Parlamentarism, Presidentialism, Constituent Assembly, Plebiscite.

\section{INTRODUCCIÓN}

En 1925 se llevó adelante un proceso de reforma a la Constitución de 1833 que no respetaba los mecanismos dispuestos para ello en el texto constitucional vigente. En efecto, mientras -en lo fundamental-, cualquier reforma exigía la intervención de dos congresos sucesivos $^{1}$, Alessandri y los militares pretenderían reformarla a través de una asamblea constituyente, aunque luego se optara por la redacción de un proyecto por una comisión nombrada por el mismo Presidente de la República, que sería sancionada luego a través de una consulta plebiscitaria. Todo ello se daba en medio de una coyuntura histórica muy especial. A partir de la elección presidencial de $1920^{2}$, que llevó al poder por primera vez a Arturo Alessandri Palma, y con particular fuerza desde la intervención militar de 1924, y

\footnotetext{
* Profesor de la Facultad de Derecho y del Instituto de Historia de la Universidad de los Andes (Chile), Doctor en Derecho por la Universidad de Frankfurt/M. Dirección Postal: Universidad de los Andes, Facultad de Derecho, A. Mons. Alvaro del Portillo 12.455, Las Condes, Santiago. Dirección electrónica: ebrahm@uandes. cl. Este artículo se enmarca en el proyecto Fondecyt regular $n^{\circ} 1151403$.

1 Constitudión de 1833, arts. 167ss. Los artículos se citarán de acuerdo a su numeración original, la que cambió en un par de números con la reforma de 1888. Además los artículos relativos al procedimiento de reforma constitucional se reformaron en 1882 .

2 Millar (1981).
} 
hasta el año 1932, Chile vivió en medio de un período revolucionario. Se trata de aquel que Mario Góngora ${ }^{3}$ ha llamado "el tiempo de los caudillos". En la superficie institucional, más allá del hecho de que formalmente entrara en vigencia la Constitución Política de 1925, se oscilaría entre los rebrotes del parlamentarismo, un presidencialismo de tipo caudillesco, la dictadura y la anarquía, en medio -por momentos- de la violencia de los enfrentamientos sociales, de las masas proletarias ocupando las calles de los principales centros urbanos y de las distintas unidades militares interviniendo, de manera inorgánica, en la política contingente. Más importante es todavía el hecho de que, como mar de fondo, tomó forma en esos años una nueva mentalidad y una nueva concepción del Estado y llegaría a su fin la república aristocrática decimonónica. Las fuerzas nuevas, que en buena medida tendrían como punta de lanza a la oficialidad joven del ejército ${ }^{4}$, terminarían por imponer un régimen presidencial; impulsarían el desarrollo de una democracia de masas y la irrupción en política de los sectores medios y populares; potenciarían el proteccionismo jurídico, que buscaba proteger a los sectores sociales considerados más débiles, y un creciente intervencionismo estatal; $y$, por último, de gran importancia para los conservadores, el avance de las tendencias secularizadoras se concretaría en la separación de la Iglesia y el Estado en la Constitución Política de $1925^{5}$.

Por otra parte debe considerarse que este proceso de cambios se sostenía en fuerzas que no eran solo circunstanciales o locales, sino que se enraizaban en un movimiento de dimensiones mundiales, que había ido tomando forma en Europa, en sus diversos aspectos, a partir de la crisis de 1873-74 y que había sufrido una clara aceleración con la Primera Guerra Mundial y sus secuelas ${ }^{6}$, y que en el ámbito del derecho constitucional se concretaría en la promulgación de constituciones tan prestigiosas como la alemana de Weimar de 1919 y la aparición de regímenes autoritarios como los de Primo de Rivera en España y Mussolini en Italia.

¿Como reaccionó el Partido Conservador, uno de los pilares en que se sostenía el orden vigente hasta 1920, ante esa vorágine de cambios que amenazaba con desarticular por completo su visión del mundo y el sistema político, social y económico en que este se concretaba y que sentía como propio? Nuestra hipótesis postula que en este contexto revolucionario los conservadores vieron cuestionada de modo tan radical su visión del mundo que se vieron obligados a adoptar una firme posición defensiva del antiguo orden, aun cuando el ambiente dominante permearía también las filas de su propio partido, por lo que no les resultaría fácil dar una respuesta unívoca a estos desafíos. Un sector importante del partido no se conformaría con volver a la institucionalidad vigente antes de la intervención militar, sino que abogaría por reformas que democratizaran el sistema, e incluso defendería la introducción de elementos corporativos y también que se consagraran derechos sociales en concordancia con la doctrina social de la Iglesia. Aquí, ya en la década de los veinte, se

\footnotetext{
3 GÓNGORA (1981) pp. 57ss.

4 Brahm(2003), Arancibia (2007) y Millar (1972-1973). Constitución de 1833, Primera disposición transitoria

5 Bravo Lira (1978), Tagle (1997), Brahm (1999 y 2012), Brahm, Bertelsen y Amunátegui (2002).

6 Gall (1978), Stolleis (1999), Schivelbusch (2008), Eichenhofer (2007).
} 
encuentra la raíz de los desgarros que sufriría el partido en los años siguientes y en cuyo estudio se ha centrado buena parte de la historiografía ${ }^{7}$.

Esta cuestión es la que se analizará en este artículo, considerando un aspecto central: la posición que adoptó el Partido Conservador ante la crisis institucional que empezó a vivir el país luego del "ruido de sables" de septiembre de 1924. Como consecuencia de esta intervención militar, el Presidente Arturo Alessandri terminó por abandonar el país, con un permiso otorgado por el Congreso Nacional, ocupando su lugar una Junta de Gobierno militar, que clausuraría las sesiones de las cámaras, la que a su vez sería derrocada por una nueva intervención militar -liderada por Carlos Ibáñez y Marmaduke Grove- en enero de 1925, que daría paso a una nueva Junta de Gobierno, la que, como la anterior, también gobernaría sin Congreso y a través de la dictación de Decretos Leyes ${ }^{8}$. Una de las primeras medidas tomadas por los golpistas de enero sería llamar de vuelta a Alessandri para que terminara su período presidencial. Su llegada al país, como luego se verá, se concretaría en el mes de marzo de 1925 y, a partir de ese momento, el Presidente constitucional pondría todo su empeño en dotar a Chile de una nueva constitución de carácter presidencialista. En ello coincidían Alessandri y los militares que lo habían invitado a volver al país. En carta de 9 de marzo del año 1925, Carlos Ibáñez, Ministro de Guerra de la Junta gobernante, le señalaba al Presidente de la República que "todo ciudadano que piensa quiere ver hoy robustecido el principio de autoridad, y consagrado el de la honradez política y administrativa"

Para el Partido Conservador, que desde la Guerra Civil de 1891 se había constituido en uno de los grandes defensores del régimen parlamentario que ahora se pretendía sustituir por el presidencial, esto constituía un gran desafío y una amenaza, más todavía cuando la reforma no se ceñiría al procedimiento constitucional vigente. Por lo demás la oposición del conservantismo a Alessandri era radical ya desde los años en que el partido constituía el pilar de la así llamada Unión Nacional. Los conservadores debían oponerse a la reforma constitucional planteada y defender el régimen parlamentario, pero ahora en un contexto distinto, en el que actuaban fuerzas nuevas, incluso dentro de sus propias huestes partidarias, aunque ello se hiciera recién evidente de forma plena y con cifras, en la elección presidencial de 1925 con el sorpresivo cerca del 30\% de los votos que obtuvo el candidato opuesto a los partidos tradicionales, José Santos Salas ${ }^{10}$.

Utilizando como fuentes, en lo fundamental, los principales medios de prensa conservadores de la época, El Diario Ilustrado de Santiago y La Unión de Valparaíso, se estudiará el actuar del Partido Conservador y el desarrollo de sus ideas constitucionales entre los meses de marzo y agosto de 1925, período durante el cual se avanza en la elaboración de la Constitución Política de 1925.

Pereira (1994), Cristi y Ruiz (1992), Correa (2004).

8 Vial (1986), Collier y Sater (1998), Scott (2009), Ahumada (1931), Monreal (1929), Millar (197273).

9 Citado según Donoso (1976) p. 277; Brahm, Bertelsen y Amunátegui (2002) p. 34.

10 Brahm (2005). 


\section{EL PARTIDO CONSERVADOR ANTE EL REGRESO DE ARTURO ALESSANDRI}

La vuelta al país del Presidente constitucional Arturo Alessandri en marzo de 1925 fue mirada con cierta esperanza por los conservadores, pese a las profundas diferencias que habían tenido con él durante los primeros años de su gobierno. Ella permitiría "terminar pronto la época de agitación, de sorpresas y de violencias que atravesamos", de "restablecer cuanto antes el régimen civil" 11 . La llegada de Alessandri debería encauzar a la República a la normalidad, terminando con "el gobierno de hecho y con las zozobras consiguientes a tan grave estado de cosas"12. Recordando su antigua enemistad, la prensa conservadora destacaba el que Alessandri hubiera usado a su llegada "el lenguaje que siempre habríamos deseado oírle, que muchas veces nos permitimos aconsejarle que empleara, porque era el que convenía a su alta dignidad, porque era el que habían usado siempre los primeros magistrados de esta nación", de tal forma que "flotaba en el ambiente una inmensa esperanza y el ferviente anhelo de la patria por volver a ser lo que fue"13.

Algo distinto era el tono del órgano representativo del conservantismo porteño, La Unión de Valparaíso. Para su editor parecía no ser tan importante el pasado, "lo que fue", sino el futuro, lo que debía venir. Luego de destacar el acto público de recepción de Alessandri como "la hora de la reconciliación de la familia chilena en el alborozo por la reinstalación del Presidente constitucional en el poder", manifestaba sus profundos anhelos democráticos: "Asistimos a una hora grave de la vida nacional, a una hora que la historia analizará. Asistimos a la hora solemne en que muere un régimen político que fue grande y glorioso para él y para la patria: al fin melancólico del gobierno de la aristocracia, tan noble, rígida y patriota como la que plasmó la república romana y cayó con Cesar; y al advenimiento de un régimen de democracia todavía indeterminado y petulante, pero fuerte e irresistible. Es la evolución de los pueblos, impulsados por la dinámica cristiana"14

“¿Qué mueve hoy a las masas chilenas?, se preguntaba el editor de La Unión de Valparaíso. Pues el cansancio que provoca lo inestable; el temor a las facciones armadas que nos arrastrarían a la guerra civil (...) El Excmo. Señor Alessandri encarna el retorno al régimen constitucional". En esa perspectiva cuenta con el apoyo de la gran mayoría de los chilenos, si bien debe gobernar en circunstancias anormales: "sin oposición, sin Congreso y con todo un pueblo que confía y espera (...) Pero nunca tampoco fue un mandatario objeto de tantas demandas y exigencias como este lo será"15.

Pero también desde muy temprano el apoyo conservador a Alessandri iba acompañado de un dejo crítico evidente. Se lo quería para poner fin a la intervención militar y volver al país a los cauces constitucionales, pero se lo miraba con particular desconfianza por lo que había sido su actuación política reciente. En esa línea, el Centro Conservador M. J.

\footnotetext{
11 Diario Ilustrado (20/3/1925) p. 3.

12 Diario Ilustrado (20/3/1925) p. 11.

13 Diario Ilustrado (21/3/1925) p. 3.

14 La Unión (22/3/1925) p. 3.

15 La Unión (21/3/1925) p. 3.
} 
Irarrázaval, veía sumido a Chile en una crisis que debía culminar con el establecimiento de un "régimen sovietista" o con la perpetuación de la "dictadura del sable, que siempre ha sido o será un oprobio en toda nación civilizada. Ante esta situación, y sin dejar de reconocer que el Presidente Alessandri es el único y principal causante de nuestra desorganización administrativa social y económica y de la dolorosa indisciplina de las fuerzas armadas de la nación, estima, guiada por un alto y sincero patriotismo que, como un mal menor, debe prestarse a su gobierno amplia y eficaz cooperación, en todo lo que tienda al restablecimiento del régimen republicano constitucional" ${ }^{16}$.

Pero a muy poco andar las esperanzas de cambio darían paso a la crítica. En su momento los conservadores habían celebrado la caída de Alessandri -la junta de gobierno de septiembre de 1924 se consideraba "restauradora" frente a los abusos en que habría incurrido su administración - "porque ella significaba la salida del Gobierno de una camarilla de logreros y gestores que hacían daños incalculable al Fisco y a la Nación”. Luego se habían alegrado de su vuelta porque esperaban terminara con el gobierno de la "junta revolucionaria" de enero de 1925, volviendo al "régimen civil"; pero esto no había ocurrido. Se criticaba el que Alessandri hubiera mantenido el mismo ministerio que actuaba desde el golpe de 23 de enero y que hubiera nombrado como edecanes presidenciales a "prominentes oficiales del Comité Militar Revolucionario", con lo que dejaba de cumplir una de sus principales promesas: "la vuelta inmediata al régimen civil y el retiro de los militares a sus funciones propias" 17 .

En un editorial publicado luego de transcurrido un mes de la vuelta al país del primer mandatario, El Diario Ilustrado hacía una crítica similar. "El Presidente había jurado en 1920 cumplir y hacer cumplir la constitución del país. El ministerio había jurado solo respetar el manifiesto del 11 de septiembre. Los telegramas del señor Alessandri anunciaban que este no reconocía otra dictadura que la de la ley. Los ministros estaban ejerciendo la dictadura de la espada. El Presidente y el ministerio no podían trabajar juntos (...) Sin embargo el señor Alessandri conservó el ministerio de la Junta Militar mientras se daba tiempo para orientarse. Pero el tiempo ha transcurrido y el ministerio no se retira" ${ }^{18}$. Más todavía, no solo seguían vigentes los Decretos Leyes dictados por ambas juntas de gobierno, sino que a través de ellos el mismo Alessandri había cohonestado algunos de los actos más violentos de los gobiernos de excepción. "La salida del último deportado, se señalaba

\footnotetext{
16 LA UnIÓN (14/3/1925) p. 3. También los conservadores manifestarían su decidida oposición a la propuesta que se hizo por algunos sectores en orden a rebautizar la Alameda como Avenida Alessandri. LA UNIÓN $(13 / 3 / 1925)$ p. 3.

17 La Unión (28/3/1925) p. 3. También sería objeto de frecuente crítica por la prensa conservadora el que Alessandri permaneciera fiel al que había sido su círculo más cercano, la "camarilla". LA UNIÓN (20/3/1925) P. 3. Mientras que frente a la intervención militar los conservadores serían siempre muy claros en distinguir la revolución de septiembre que había terminado con la salida de Alessandri y la formación de una Junta de oficiales de alta graduación, que algo se acercaba a sus postulados, de la de enero que había llevado de vuelta al poder a la oficialidad joven y revolucionaria. LA UNIÓN (29/4/1925) P. 3.1. Cfr. VIAL (1986).

18 Diario Ilustrado (22/4/1925) p. 5.
} 
en La Unión, señor del Solar, estando a la cabeza del Ejecutivo el Sr. Alessandri, dice al país que aún subsiste el imperio militar en la Moneda"19.

Para los conservadores resultaba intolerable que en la práctica siguieran detentando el poder los militares revolucionarios de enero de 1925, entre ellos Carlos Ibáñez, ministro de Guerra. "El Presidente de la República está preso en las redes que le han tendido los que tramaron la conspiración del 23 de enero y designaron, como sus representantes, a los actuales ministros"20. El editorialista de La Unión planteaba la duda de "si el Presidente de la República es un rehén del Ejército o si el Ejército es una pantalla del Presidente. En ambos casos hay un peligro latente para la República" ${ }^{21}$. Y otro artículo llevaba un título que llamaba a la acción: "S.E. debe deshacerse de los militares"22. En opinión de los conservadores, el Ejército había sufrido en los últimos meses un notable cambio: "de fuerza esencialmente obediente según la Constitución, se ha transformado en fuerza esencialmente gobernante"23. Más todavía, el problema de fondo que representaba esta presencia del Ejército en el gobierno de Alessandri, esta "cierta asiduidad militar en la Moneda", es que con ese apoyo el Presidente de la República buscaba imponer un régimen de gobierno "representativo", dotando al ejecutivo de "una gran suma de facultades", régimen que ya en su momento el país habría "repudiado por centralista, por demasiado personal, por antidemocrático y peligroso" 24 .

Ante esta amenaza, la aspiración de los conservadores y de los demás partidos tradicionales, como el Radical, era el que se volviera a la plena vigencia de la Constitución Política de 1833 y al régimen parlamentario que con ella se practicaba desde 1891. "Los que han invocado la vigencia de la Constitución, se señalaba en el Diario Ilustrado, para pedir el regreso del Presidente elegido en junio de 1920 para que termine su período legal, no andan en la lógica cuando se oponen a la reunión del Congreso y a la vigencia de esa misma Constitución" ${ }^{25}$. Y más adelante se señalaba en el tradicional periódico conservador: "El señor Alessandri representa el regreso a la Constitución (...) Por restablecimiento de la normalidad constitucional entendemos nosotros en estos momentos la extinción del régimen militar y la preparación inmediata al advenimiento de elecciones libres, con derogación instantánea de las leyes restrictivas de la emisión del pensamiento y de las garantías individuales" ${ }^{26}$. El temor de fondo era que se perpetuara, más allá de lo que pudiera hacer Alessandri, una dictadura militar, o que esta diera paso a un gobierno revolucionario de ex-

\footnotetext{
19 La UnIÓN (26/3/1925) p. 3. Más adelante agregaba que "aún no vemos un paso resuelto hacia la regularidad constitucional y la civilidad efectiva del Gobierno. Solo uno: el envío a Europa del señor Dartnell. Es preciso inventar otras comisiones a Europa para otros militares, a fin de que vayan a reposar de sus enormes actividades revolucionarias".

20 La Unión (29/3/1925) p. 3. “¿Está prisionero en la Moneda el señor Alessandri o no lo está?”, se preguntaba el editorialista de LA UNIÓN (5/4/1925) p. 3.

21 La Unión (15/4/1925) p. 3.

22 La Unión (15/4/1925) p. 3.

23 La Unión (8/5/1925) p. 3. Constitución de 1833, art. 157.

24 La Unión (2/4/1925) p. 3.

25 Diario Ilustrado (7/3/1925) p. 3. La Unión (13/3/1925) p. 3.

26 Diario Ilustrado (21/3/1925) p. 11.
} 
trema izquierda; como consecuencia se debía combatir "el peligro real y efectivo que existe del sovietismo, que se ve a corta distancia y del militarismo que es una dolorosa realidad" 27 .

Para precaver esos peligros y, sobre todo, para poner fin a la intervención militar en la política contingente e, indirectamente, unificar sus fuerzas contra el alessandrismo, los partidos políticos tradicionales, encabezados por radicales y conservadores, se pondrían de acuerdo para dar forma a un así llamado "Frente Civil"28. Todo ello reflejaba que seguían habiendo diferencias muy de fondo entre el gobierno y los sectores de la oposición partidista-civil. Como lo expresaba de forma irónica un artículo editorial del Diario Ilustrado: "Al Presidente de la República se le concede licencia por medio de una revolución; y por medio de dos revoluciones, se pone término al permiso (...) El Ejército es esencialmente obediente, y delibera (...) La Cámara es esencialmente desobediente, pero no puede deliberar (...) La tropa asciende por actos de disciplina, y sus jefes por actos de indisciplina (...) Los ministros juran en serio por el Manifiesto del 11 de septiembre (...) Los partidos no creen en la existencia del gobierno civil y el gobierno militar no cree en la existencia de los partidos civiles" 29 .

Las críticas más constantes de la dirigencia y de la prensa conservadora se dirigían a algunos aspectos muy concretos del ejercicio del poder por parte del gobierno. De partida, el que se hubiera perseguido y deportado a una serie de dirigentes partidistas ${ }^{30}$. También el que no se gozara de plena libertad de prensa y que los periodistas estuvieran siempre sujetos a todo tipo de amenazas por parte del círculo militar y de autoridades de gobierno, violando el art. $12 \mathrm{~N}^{\circ} 7$ de la Constitución de $1833^{31}$. Un ejemplo al canto. Durante el mes de mayo el senador Guillermo Bañados publicó una serie de artículos en que recordaba que, de acuerdo a la Constitución (art. 52), el 1 de junio era el día fijado para la apertura de las Cámaras, por lo que señalaba que "los congresales estamos obligados por el mandato que hemos recibido a concurrir a sesiones ordinarias desde el $1^{\circ}$ de junio" ${ }^{2}$. Ante esto Alessandri habría llamado al Subdirector del Diario Ilustrado para amenazarlo con la clausura si es que volvía a publicar artículos de ese tenor ${ }^{33}$. En otra ocasión sería el Inspector General del Ejército, Mariano Navarrete quien comunicaría a las autoridades del mismo medio de prensa que si insistían "en lanzar artículos ofensivos para la dignidad y el prestigio del Ejército y sus miembros, la fuerza pública procederá a clausurarlo sin consideración alguna” 34 . Se denostaba también la profusa dictación de decretos leyes por parte de los gobiernos de excepción. Las dos juntas de gobierno, "desde Septiembre de 1924 hasta el 20 de marzo de 1925 , dictaron, firmaron y promulgaron 446 decretos leyes que todo el mundo ignora, salvo pequeñas excepciones, con la agravante de que de estos decretos leyes, la segunda Junta,

27 Declaraciones del Presidente de los Conservadores de Valparaíso, sr. Moya Figueroa, La Unión (15/04/1925) p. 3. La Unión (15/4/1925) p. 3.

28 Diario Ilustrado $(1 / 4 / 1925)$ p. 3.

29 Diario Ilustrado (14/4/1925) p. 3. Constitución de 1833, arts. 76 y 157.

30 Diario Ilustrado (29/4/1925) p. 3.

31 Diario Ilustrado $(4 / 3 / 1925)$ p. 3.

32 Diario Ilustrado (25/5/1925) p. 9.

33 Diario Ilustrado (26/5/1925) p. 3. La Unión (26/5/1925) p. 1.

34 Diario Ilustrado (8/6/1925) p. 3. 
en solo DOS MESES firmó y SANCIONO 220"; decretos leyes que no deberían aplicarse "hasta que el país decida qué hacer con ellos" 35 . Por último, el que volvieran a nombrarse a autoridades locales -intendentes y gobernadores- que habrían tenido activa participación en los fraudes electorales ocurridos en la últimas elecciones, en un momento en que debería recurrirse a ellas, sea para generar una Asamblea Constituyente o para elegir el Congreso ${ }^{36}$. "Los señores Dávila, Silva y de la Maza (gobernador de Magallanes, intendente de Atacama e intendente del Bío-Bío) fueron de los más bravos y audaces interventores del 2 de marzo" 37 .

\section{III. ¿DIVISIONES EN EL PARTIDO CONSERVADOR?}

La discusión que debía llevar a la entrada en vigencia de la nueva Constitución Política se daba en medio de un ambiente nuevo y muy especial. Todos los actores políticos captaban que se vivía una época revolucionaria y solo se dudaba de cuál sería el destino final de ese proceso. Comentando el fin de la Primera Guerra Mundial y los tratados de paz que la siguieron se señalaba en La Unión de Valparaíso: "Aquel verbo de redención de los humildes, nacido en los dolores de la guerra, entre razas diezmadas y entre el hambre y toda casta de miserias, encontró aquí corazones anhelantes, cuyas ambiciones se originaron en su pobreza y en la incesante propaganda por un Estado ideal, cimentado sobre fuertes contribuciones a la fortuna y sobre el hecho de entregar el gobierno a los débiles, quitándoselo a los poderosos (...) Toda nuestra vieja y egoísta oligarquía -el egoísmo la ha perdido- empezó a crujir el año 20, bajo el peso de un pueblo ansioso de poder y de mejoras económicas. La verba caldeada y sugestionadora del señor Alessandri dio forma a esas aspiraciones y suministró a las masas un caudillo". Pero su gobierno habría sido estéril y terminó en la dictadura que provocaría el golpe militar de enero, prueba de que el país seguía viviendo en una época revolucionaria. "El motor principal de todas estas catástrofes políticas y económicas, concluía el articulista conservador porteño, es el legítimo deseo de las clases trabajadoras, representadas por una parte pequeña de la oligarquía obrera de las grandes ciudades, de tener una holgada situación económica y una gran influencia y acción política" 38 .

Sin duda que el ambiente dominante, como se ve por el editorial recién citado, influyó también en el seno del Partido Conservador. Empezaba el mes de marzo de 1925 cuando algunos sectores de la juventud del partido, encabezados por Ricardo Boizard, propiciaron la constitución de un movimiento de unión de la juventud de todos los partidos, sobre la base del reconocimiento del gobierno revolucionario (en cuanto este estaba en manos de los militares) y de dar su apoyo a Arturo Alessandri para que este pudiera poner término a su período presidencial, lo que de inmediato generó las críticas de otro sector del partido.

\footnotetext{
35 La Unión (24/4/1925) p. 3.

36 Diario Ilustrado (3/4/1925) p. 3.

37 Diario Ilustrado (21/4/1925) p. 3.

38 La Unión $(9 / 5 / 1925)$ p. 3.
} 
No en vano ese gobierno mantenía deportados a importantes líderes conservadores ${ }^{39}$. Por su parte la "Asamblea de propaganda conservadora" aprobaba un voto relativo a la próxima convención del partido, en el que luego de criticar la restringida participación que correspondería en ella a las bases conservadoras, sobre todo a la juventud y a los obreros, proponía ampliarla para hacer posible la verdadera "democracia cristiana" y la descentralización del partido ${ }^{40}$. Ya el 1 de abril, una vez designados los delegados departamentales a la gran convención del Partido, en el Diario Ilustrado se afirmaba que "la elección hecha por la asamblea departamental es una acertada selección de representantes de todas las corrientes y matices del partido, notándose, sin embargo, una marcada tendencia democrática, lo que augura una brillante defensa de estos principios" ${ }^{\text {"1 }}$.

Estos antecedentes, entre otros, son los que llevaban a afirmar a Guillermo Piedrabuena, alto dirigente Conservador, que "no es un misterio que en el partido se notan dos tendencias bien marcadas para llevar a la práctica el ideal que sirve de bandera y de programa (...) Una formada por la aristocracia, por los hombres que representan las tradiciones y otra por todo el elemento modesto, obreros y juventud que constituyen la esperanza y el porvenir" ${ }^{\prime 2}$.

En esta línea resulta de particular interés considerar las apreciaciones y los acuerdos a los que se llegó a mediados del mes de abril de 1925 en una sesión de la Asamblea de Propaganda Conservadora, presidida por Misael Pradenas, que se preparaba para la gran Convención del partido que tendría lugar en el mes de junio. Allí se aprobó un "programa mínimo de acción conservadora", en el que se proponía, entre otras cosas, el "cambio de nombre del Partido, denominándose "Partido Social Cristiano" o "Partido Demócrata Cristiano" o bien "Partido Católico". Para avanzar en la democratización del mismo se postulaba "modificar la composición del Directorio General en el sentido de que no formen parte de él las fuerzas muertas como ser: los ex parlamentarios, ex ministros de Estado, ex diplomáticos, ex consejeros de Estado; que la Convención elija solo un número reducido. Los demás miembros deben ser los delegados de las Asambleas Departamentales" ${ }^{43}$. Llama la atención también que la cobertura de esta reunión sería más pronta, mayor y más completa en La Unión de Valparaíso que en el Diario Ilustrado. Por ejemplo, en este último periódico conservador se excluía el medular párrafo siguiente: "Para la juventud y para el obrero "El Diario Ilustrado" es el órgano del catolicismo aristocrático, es el órgano de la dirección actual del Partido, que solo representa la tendencia antigua; intertanto "La Unión” de Valparaíso, que con orgullo creemos el mejor diario de Chile, se distingue por su amplitud de criterio, por sus campañas nobles y desinteresadas, y sobre todo porque la anima un espíritu francamente democrático, por lo mismo que respira un catolicismo puro e inmaculado" ${ }^{4}$.

39 Diario Ilustrado (7, 8 y 9/3/1925) pp. 15 y 17.

40 Diario Ilustrado (27/3/1925) p. 14

41 Diario Ilustrado $(1 / 4 / 1925)$ p. 9.

42 Diario Ilustrado (28/3/1925) p. 14.

43 La Unión (15/4/1925) p. 3 y Diario Ilustrado (18/4/1925) p. 3.

44 La Unión (15/4/1925) p. 9. 
La verdad es que no solo La Unión, sino, en general, los conservadores de Valparaíso mantenían una serie de diferencias con los de Santiago, que incluso los había llevado a apartarse del mismo por un par de años, división que solo se superó en enero de 1925. Como señalaba el Presidente de la Asamblea Conservadora del puerto, Aníbal Moya, "la solución de nuestro divorcio con Santiago ha sido hecha a base de llevar a la práctica nuestros anhelos democráticos” ${ }^{45}$. Más todavía, en Valparaíso había sectores importantes de reformistas dentro del conservantismo. En un artículo titulado "La Democracia Cristiana y las reformas constitucionales" se señalaba en La Unión que "nuestros anhelos de demócratas cristianos convencidos, no se detienen en meras reformas constitucionales, sino que deseamos que se elabore una nueva Carta Fundamental que permita romper el estrecho molde de egoísmo liberal y evitando violentos trastornos sociales, consigamos sacudirnos del oprobioso régimen capitalista" ${ }^{\$ 6}$.

Pero, al mismo tiempo, también en Valparaíso había conservadores que disentían de la directiva partidaria de Santiago -que se identificaría con "las ideas enciclopedistas del libre pensamiento"- desde la perspectiva del tradicionalismo católico. "El individualismo egoísta, como fruto de ideales extraviados, se señalaba en un artículo editorial de La Unión, no puede llevar a resultados beneficiosos. Es la vía de la organización gremial cristiana la sola que puede llevar al progreso del país, a la paz social y al bienestar de todos y cada uno" ${ }^{47}$. Se levantaba así el corporativismo como alternativa frente al sistema de partidos dominante en la política chilena. "Ya el individuo no se presenta aislado en el campo del trabajo", se señalaba en otro editorial, "sino tal como León XIII, consultando el derecho natural, deseaba que se organizasen los hombres: formando corporaciones organizadas” 48 .

El embate corporativista sería frenado en seco desde las páginas de El Diario Ilustrado, pues iba directamente en contra de la existencia misma del Partido Conservador. Tanto este medio santiaguino como la directiva central conservadora no aceptarían que se levantara en reemplazo de los partidos "ya sea una supuesta organización gremial, ya unas presuntas fuerzas vivas que no se sabe dónde están o qué persiguen” ${ }^{39}$. No solo se consideraba que la representación gremial era inadecuada para dar forma a una Asamblea Constituyente, que era el tema del momento, porque en ella se discutirían cuestiones políticas y no económicas, sino que, en un sentido más general, se consideraba que el corporativismo resultaba algo impracticable en Chile. "Por de pronto, se señalaba en un editorial, no existen organizados en Chile ni la vigésima parte de los gremios que significan grandes actividades nacionales. Y los que están organizados no puede decirse que representen genuinamente, a todos, ni siquiera a la mayoría de los interesados" $" 50$.

La posición más de "avanzada" de los conservadores y del diario La Unión de Valparaíso se nota también en la actitud que adoptaron frente a los modelos internacionales

\footnotetext{
45 La Unión $(25 / 5 / 1925)$ p. 1.

46 La Unión (25/3/1925) p. 9.

47 La Unión (9/4/1925) p. 3.

48 La Unión (2/5/1925) p. 3.

49 Diario Ilustrado (6/7/1925) p. 11.

50 Diario Ilustrado (22/4/1925) p. 5, y (20/4/1925) p. 3.
} 
del conservantismo. Por ejemplo, además de mostrarse particularmente interesados por el desenlace de las elecciones presidenciales alemanas que tendrían lugar en 1925, destacaban el hecho de que en ese país los conservadores -el "Zentrum Partei”- gobernara junto con los socialistas y demócratas en la llamada "Coalición de Weimar". Por otra parte, ya que el candidato que correría contra Hindenburg debía ser un católico, parecía preferir entre otros nombres posibles al Dr. Wirth, "uno de los jóvenes más notables de Alemania y jefe de la juventud católico-social entre los católicos. Sus ideas son extremadas en cuestión social, defendiendo las encíclicas de León XIII con todo el radicalismo compatible con el derecho de la burguesía" " Al final el candidato sería el Dr. Marx, quién resultaría derrotado por el ex general Paul von Hindenburg, atribuyéndose la derrota al hecho de que los católicos bávaros no habrían apoyado a Marx. Ello se explicaría por la división que se habría dado al interior del catolicismo político alemán. Por un lado estaría "la rama social a lo León XIII, compuesta por unos 5 millones de votantes prusianos, acaudillados actualmente por los doctores Wirth y Marx"; por el otro "la rama católico-liberal a lo manchesteriano, constituida por el millón y medio de electores bávaros" 52 . Parecía quererse asimilar la situación alemana a la chilena, en la que también se vislumbraría una división de ese tipo. Y lo mismo se entendía pasaba en Bélgica, donde se había disuelto la coalición de católicos y liberales, porque "los católicos de la juventud no veían con buenos ojos una alianza con liberales cuyos principios individualistas y meramente utilitarios no se compaginan con la democracia cristiana" ${ }^{53}$.

\section{LA DISCUSIÓN EN TORNO A LOS MECANISMOS PARA REFORMAR LA CONSTITUCIÓN}

Con el "ruido de sables", la intervención militar de 1924, que culminó con la salida con permiso del país del Presidente de la República Arturo Alessandri, se empezó a vivir en Chile una crisis constitucional ${ }^{54}$. Esto era así no solo porque el gobernante se veía impedido de seguir detentando el poder debido a un acto de fuerza, de deliberación mili$\operatorname{tar}^{55}$, sino también por el hecho de que la misma oficialidad joven del Ejército que se estaba transformando en el actor central de la política chilena, exigía una reforma constitucional que pusiera fin al régimen parlamentario. Más todavía, para alcanzar este objetivo los oficiales, organizados ahora en una "Junta Militar", plantearon la necesidad de generar "una Carta Fundamental que corresponda a las aspiraciones nacionales”, la que debía ser elaborada por una "libre Asamblea Constituyente" ${ }^{56}$, sin considerar lo dispuesto en los artículos 165ss. de la Constitución de 1833. Esta propuesta iría tomando cada vez mayor fuerza. Una de las razones por las que terminó por caer la Junta de Gobierno Altamirano-Nef-Ben-

51 La Unión (29/3/1925) p. 10.

52 LA Unión $(18 / 5 / 1925)$ p. 3.

53 La Unión $(27 / 4 / 1925)$ p. 3.

54 Sobre la intervención militar de 1924 pueden consultarse, Ahumada (1925), Rodríguez (1938), MonREAL (1929), Sáez (1933-1934), Millar (1972-73), Vial (1986).

55 Constitución de 1833, art. 157.

56 Escobar y Iluvic (1984). 
net, según Gonzalo Vial, habría sido el que esta habría buscado reemplazar la constituyente por el Congreso que debía elegirse en 1925. La Constituyente sería defendida también por los revolucionarios de enero, Ibáñez y Grove; la reclamaban los partidos de la Alianza Liberal, además de fuerzas estudiantiles y obreras, y la anunció Arturo Alessandri en su famoso "telegrama de Roma", de enero de 1925 en el que comunicaba su vuelta al país, haciendo suyos los principios sustentados por el movimiento militar de septiembre ${ }^{57}$.

Una vez en Chile, habiendo reasumido la primera magistratura, Alessandri insistiría en la misma idea en reiteradas oportunidades: ante la "Convención de la Juventud de los Partidos Avanzados" el 23 de marzo; por esas mismas fechas en un acto público celebrado por la ANEC y el 5 de abril, ante oficiales de ejército en la Escuela de Caballería ${ }^{58}$.

El llamado a la Constituyente constituiría también un elemento central del discurso que pronunciaría el primer mandatario ante la reunión de "notables" celebrada en el salón de honor de la Presidencia de la República el 3 de abril y a la que el mismo había citado. En esa ocasión señalaba que, "por mucho que he pensado no encuentro otro medio para volver a la regularidad constitucional que la organización de una Constituyente que dé una nueva Constitución al país", aunque por esa vía se violaba lo dispuesto en el texto constitucional vigente ${ }^{59}$. Y en cuanto a la forma como esta debería organizarse agregaba que, "mi pensamiento sería hacer esta Constituyente con dos tercios de elección popular, y el tercio restante con representación de las actividades, de las fuerzas vivas de la Nación, por ejemplo la Universidad, el Ejército, la Marina, la Iglesia, representada por sus jefes, las actividades obreras, algunos gremios que tienen importancia en la vida de la República"60.

¿Como reaccionó el Partido Conservador ante estos llamados a reformar la constitución vigente y, en el fondo, a reemplazarla por un texto nuevo, a través de una asamblea constituyente?

Desde el principio se dio una reacción prácticamente unánime en torno a la idea de defender la vigencia de la Constitución Política de 1833, que siempre había sido considerada una de las grandes obras del partido y en la que residiría en buena parte la explicación de la excepcionalidad chilena en el contexto hispanoamericano ${ }^{61}$. Tendría esta además la ventaja de su flexibilidad; no en vano había hecho posible que Chile pasara de un régimen presidencial a uno, por lo menos en la práctica, de tipo parlamentario, sin que tuvieran que introducirse cambios mayores en el texto constitucional vigente. Por eso es que el Diario Ilustrado reaccionaba de inmediato con desazón al conocer el discurso pronunciado por el Presidente Alessandri frente a los notables, antes citado, señalando que como consecuencia, "el país puede darse definitivamente por notificado de que la Constitución nacional que nos regía desde 1833, ha muerto" ${ }^{62}$. De ahí que parecía llegado el momento de "formar

\footnotetext{
57 Vial (1986) pp. 501 y 532. No en vano, todavía el 7 de abril de 1925, en la primera sesión de la Comisión Consultiva que debía trabajar en la reforma constitucional, señalaba que estaba "aquí sirviendo los ideales de la revolución”. ACtas Oficiales (1925) p. 9.

58 VIAL (1986) p. 534.

59 Constitución de 1833 , arts. 165ss.

60 La Unión (5/4/1925) p. 11.

61 Para la Constitución Política de 1833 puede consultarse BraHm (2007).

62 Diario Ilustrado (5/4/1925) p. 7.
} 
una "Sociedad de los Amigos de la Constitución del 33", para defenderla de acusaciones de la que era inocente. "Se la culpa de las desgracias del país, especialmente las de los últimos años, sin querer tomar nota de que esas desgracias tuvieron su principio en las violaciones de la Constitución" ${ }^{63}$.

Más todavía, se argumentaba que los países serios, como lo había sido siempre Chile, se caracterizaban por su gran estabilidad institucional. De ahí que, de cambiarse la constitución, "entraríamos por el camino de los caudillos tropicales. Casi no hay revolución en esta tembladera política sudamericana que no levante como enseña y como tapujo de personales ambiciones, una Constitución. Cada soldadote de largas botas y sable rastrero, lleva en las alforjas un proyecto de Constitución. Y hay que reconocer que para el progreso de esos países tanto ha dado una como otra" ${ }^{64}$.

Por otra parte, si se trataba de reformar la constitución vigente, se consideraba que para ello no correspondía llamar a elecciones para una asamblea constituyente. Se estimaba por los conservadores que esta sería un medio "revolucionario" 65.

Al respecto La Unión de Valparaíso reproducía un artículo publicado originalmente en El Chileno de La Serena en el que se demostraba el carácter inconstitucional de la constituyente. Luego de citar el art. $3^{\circ}$ de la Constitución de 1833, señalaba que "la Asamblea Constituyente proyectada no es autoridad establecida por nuestra Constitución y no puede, por lo tanto, ser depositaria de la soberanía nacional". Con ella se violaba también el art. 11, en cuanto ella "no es Congreso Nacional; y por consiguiente no puede legislar ni hacer la primera de las leyes que es la Carta Constitucional". Por último, por contradecir directamente los arts. 150 y 151 de la Constitución de 1833, la Constituyente sería "una Asamblea sediciosa, es decir, criminal y responsable ante el Código Penal” y sus actos serían "absolutamente nulos"66.

Como se ha dicho en otro lugar, el conservantismo celebró la intervención militar de septiembre de 1924, entendida como un movimiento "restaurador" que terminaría con los abusos del alessandrismo, pero criticó de inmediato "la fantasía de la Constituyente" contenida en el "Manifiesto" del 11 de septiembre ${ }^{67}$. Se entendía que se estaba dando "la espalda a la Constitución del 33 sea para renovarla, sea para reformarla sin respeto de sus reglas de reforma" ${ }^{68}$. Si se la quería reformar se lo debería hacer "conforme a su ritualidad"69. Resultaba evidente a esas alturas que tanto Alessandri como los militares pretendían poner fin al régimen parlamentario practicado desde 1891 y que los conservadores defendían, a través del medio revolucionario de la constituyente. Ante ello los conservadores propondrían

\footnotetext{
63 Diario Ilustrado (10/4/1925) p. 3.

64 La Unión (27/3/1925) p. 3.2. Cfr. El Diario Ilustrado (5/4/1925) p. 7.

65 Diario Ilustrado (18/4/1925) p. 9. Pudo haber influido también el temor de que esta terminara dominada por la izquierda. LA UNIÓN (28/3/1925) p. 6 reproducía una entrevista hecha por un medio bonaerense al líder comunista chileno Manuel Hidalgo en el que este se jactaba de que la clase obrera obtendría la mayoría en la próxima Asamblea Constituyente.

66 La Unión (4/4/1925) p. 3.

67 Diario Ilustrado (26/3/1925) p. 3.

68 Diario Ilustrado $(18 / 4 / 1925)$ p. 3.

69 Diario Ilustrado $(26 / 3 / 1925)$ p. 3.
} 
como mal menor, "el que la reforma la haga la autoridad constitucional y con los trámites que la Carta Fundamental ha establecido"70. Según señalaba Antonio Varas en el Diario Ilustrado, para ello debería convocarse "al Congreso a sesiones extraordinarias por un plazo breve y limitado con el solo objeto de aprobar las reformas constitucionales que le someta el Presidente de la República”, tras lo cual debería acordar su disolución, debiendo tener lugar nuevas elecciones parlamentarias. Este nuevo parlamento, de acuerdo a lo prescrito en la Constitución, es el que tendría el carácter de constituyente y estaría en condiciones de estudiar las reformas propuestas ${ }^{71}$.

La directiva nacional del Partido, en cambio, no tendría una posición tan clara como la de la prensa conservadora. En efecto, en la reunión de "notables" citada por Alessandri para el 4 de abril, ante los anuncios dados por el mandatario en orden a la forma como se iba a llevar adelante el proceso de reformas constitucionales, el presidente del partido Arturo Lyon señaló que "obedeciendo a un alto deber patriótico, venía en declarar que el Partido que representaba en esos momentos cooperaría eficazmente a las reformas constitucionales enunciadas por el Presidente de la República" e incluso que los conservadores participarían en la Comisión de reformas anunciada por el primer mandatario ${ }^{72}$. Como bien se sabe, Alessandri anunció en ese acto la creación de dos comisiones: una para trabajar en la formalización de la constituyente y otra para estudiar las reformas constitucionales, pero al final terminaría por desestimar la idea de la constituyente ${ }^{73}$, por lo que el trabajo se concentró fundamentalmente en la última de las comisiones señaladas. En la Subcomisión de Reformas Constitucionales participarían dos políticos conservadores, Romualdo Silva Cortés y Francisco Vidal Garcés, quienes no serían considerados representantes oficiales del partido, y solo habrían cooperado con el gobierno en carácter personal, como "un tributo a ideas de concordia nacional" 74 . El mismo Silva Cortés, en carta a Alessandri, le señalaba que aceptaba su nombramiento, "porque se trata de servir a mi Patria en la más difícil situación de su historia”, aunque habría preferido que la reforma se ajustara a los procedimientos considerados en la constitución vigente ${ }^{75}$.

Esta actitud de cooperación de las cúpulas partidarias encontraría fuerte oposición en algunos sectores del conservantismo. Quizá si el caso más representativo lo sería el del vicepresidente del partido y Director del Diario Ilustrado, Rafael Luis Gumucio. En carta abierta dirigida a Arturo Lyon señalaba con dureza: "He estado en desacuerdo sobre puntos fundamentales de la actitud del partido (...) En vez de una política de abierta y enérgica oposición o, al menos, de prescindencia y protesta contra el régimen dictatorial imperante, el partido en la realidad, ha seguido prácticamente una política de aceptación o cooperación, exteriorizada, en especial con la concurrencia a las comisiones preparatorias de una nueva constitución (...) He estado y estoy en desacuerdo con esto", considerando entre

\footnotetext{
Diario Ilustrado (26/3/1925) p. 3.

1 Diario Ilustrado (7/4/1925) p. 3. Cfr. La Unión (27/3/1925) p. 3.

2 Diario Ilustrado (5/4/1925) p. 23.

3 Vial (1986) pp. 534ss. Y Alessandri (1967) p. 125.

74 Diario Ilustrado (30/7/1925) p. 10.

75 Diario Ilustrado $(11 / 4 / 1925)$ p. 3.
} 
otras cosas que seguían en el destierro varios dirigentes conservadores, que el Presidente atacaba constantemente a los partidos políticos y que seguía en la Moneda la camarilla de siempre. Por último, argumentaba Gumucio, "el Presidente de la República ha declarado oficialmente que no rige y aún que está arrasada y no existe la Constitución del Estado, que es base de nuestras instituciones republicanas y que, además, fue obra conservadora y ha sido defendida por los conservadores en noventa y dos años de vida política. Y me ha parecido que con el concurso en los preparativos inconstitucionales de una nueva Constitución, se acepta tal declaración, se toma responsabilidad en ese atentado revolucionario y se abandona una actitud tradicional"76.

De alguna manera la postura de Gumucio se vería confirmada en los hechos el mismo día en que hacía llegar su carta de renuncia al Presidente del partido. En efecto, pues sería precisamente en la sesión del 23 de julio de la Comisión que estudiaba el proyecto de reforma constitucional en la que intervendría el general Navarrete, Inspector General del Ejército, para apoyar a Alessandri exigiendo de forma amenazante el establecimiento de un régimen de gobierno presidencial ${ }^{77}$, lo que provocaría el retiro de la Comisión de los representantes conservadores, junto a otros miembros de la misma y la protesta de la prensa partidaria, para la que lo ocurrido era una prueba más de que el período revolucionario no había terminado ${ }^{78}$.

Ya que no habría Asamblea Constituyente, Alessandri se decidiría por plebiscitar el proyecto de Constitución aprobado por la Comisión, decisión que tampoco era compartida por los conservadores. De aplicarse ese mecanismo, "la verdadera fuente de la Constitución sería el señor Alessandri. Tampoco es democrático. Un país de cuatro millones de habitantes no puede dictaminar directa, prácticamente, sobre las numerosas cuestiones complejas que una constitución encierra; puede pronunciarse solamente sobre una cuestión sencilla. La soberanía popular está obligada a delegar sus funciones, como se ve en todas las democracias modernas"79. Para poner fin a la situación revolucionaria se debía "no solo evitar la Constituyente, sino también el plebiscito, y respetar la antigua Constitución”, señalaba el editorialista del Diario Ilustrado ${ }^{80}$.

En lo inmediato el Partido Conservador debería pronunciarse sobre la posición que asumiría frente al plebiscito que debería verificarse el día 30 de agosto. De acuerdo a lo que se ha visto, si los conservadores participaban en el mismo, de alguna manera debía entenderse que estaban legitimando los procedimientos que habían combatido de manera constante en los últimos meses. Más todavía, con ello parecería que estaban dando su aprobación a la revolución y a los medios revolucionarios de que esta se servía. De ahí que no pueda extrañar el que al constituirse el 15 de agosto el nuevo Directorio del partido y discutirse en el seno de esa asamblea la actitud que se debía adoptar frente al plebiscito, se impusiera mayoritariamente la posición de quienes llamaban a la abstención. "El Directo-

\footnotetext{
76 Diario Ilustrado (23/7/1925) p. 13.

77 ACTAS (1925) pp. 437ss.

78 Diario Ilustrado (24/7/1925) p. 3.

79 Diario Ilustrado (29/5/1925) p. 9.

80 Diario Ilustrado (20/6/1925) p. 3.
} 
rio General del Partido Conservador, se señalaba en la resolución correspondiente, considerando, por una parte, que la Constitución de 1833, en derecho está vigente y no puede reformarse sino del modo que ella misma establece, y, considerando, por otra parte, que la forma de consulta plebiscitaria no permite a los ciudadanos expresar sus opiniones en el punto fundamental y que no hay garantías de libertad y de corrección para el referéndum popular, acuerda: Que los conservadores se abstengan de concurrir al plebiscito del 30 de agosto" ${ }^{81}$. Pero para que no se entendiera esa decisión como una especie de renuncia o de acto de comodidad de los conservadores, también se impuso en medio de la discusión la idea de que esa abstención debía ser "activa". Para ello se debía "formar a la opinión; ilustrar a las masas; golpear la conciencia pública; demostrar la gravedad de las consecuencias que pueden derivarse para el país con la aprobación de la reforma constitucional, en la forma como se la piensa realizar" ${ }^{82}$.

\section{LAS CRÍTICAS A LA REFORMA CONSTITUCIONAL}

Desde el momento en que los conservadores se habían alzado como grandes defensores de la institucionalidad vigente, resulta evidente que se opondrían decididamente a las propuestas defendidas tanto por Alessandri como por el movimiento de la oficialidad joven del Ejército en orden a reemplazar el régimen parlamentario por uno presidencial. Por lo demás, esa sería la posición sustentada por la mayoría de los partidos tradicionales y hasta por los comunistas ${ }^{83}$. Incluso un importante referente de izquierda que sesionó en esos días, La Gran Convención de la Juventud Avanzada, se pronunciaría en favor del régimen parlamentario ${ }^{84}$

Apenas comenzó a sesionar la Subcomisión de reformas constitucionales, sus integrantes conservadores manifestaron su opinión favorable al régimen parlamentario, sin perjuicio de que aceptaran se le introdujeran algunas correcciones, de acuerdo en buena medida al contenido de un proyecto de reforma constitucional que había sido aprobado en primer trámite constitucional por el Congreso Nacional en febrero de $1924^{85}$. Francisco Vidal Garcés, por ejemplo, luego de manifestar su "opinión contraria a la supresión del régimen parlamentario", señalaba que había estudiado "todos los regímenes de Gobierno hasta llegar al sistema representativo establecido por la nueva Constitución alemana (la de Weimar de 1919) y, como consecuencia de su estudio, se confirma cada vez más en sus simpatías por el régimen parlamentario. Considera que no es el régimen el malo sino los hombres, los mismos hombres que van a aplicar mañana las reformas que aquí se estudian; de modo que alienta pocas esperanzas en orden a los efectos que ellas puedan producir en beneficio de la administración pública" ${ }^{" 6}$. Esta posición la refrendarían al final del proceso,

81 Diario Ilustrado (17/8/1925) p. 11. Cfr. Diario Ilustrado (16/8/1925) p. 11.

82 Diario Ilustrado (18/8/1925) p. 9.

83 Vial (1986) pp. 539ss., ACtas (1926) pp. 401 ss.

${ }^{84}$ La Unión (24/3/1925) p. 5.

85 Donoso (1980).

86 ACTAS (1925) p. 61. Romualdo Silva Cortés, en la misma ocasión, expresaba "su opinión favorable a un régimen parlamentario corregido". ACTAS (1925) p. 62. 
en la sesión de la Comisión Consultiva de Reformas Constitucionales de 22 de julio de 1925. El mismo Vidal Garcés señalaría en esa oportunidad que los conservadores "han sido y siguen siendo afectos al sistema parlamentario, porque, en su entender es acaso la única forma de gobierno que garantiza real y efectivamente los derechos que el proyecto mencionado y la Constitución del 33 aseguran a los individuos en la sociedad; que han sido y siguen siendo partidarios de tal sistema porque a su modo de ver, es el único que evita, que aminora, y en ciertos casos sanciona políticamente los abusos del poder ejecutivo". Su ventaja estaría también en que el parlamento "representa genuinamente al pueblo e interpreta su espíritu y tendencias mejor que ningún otro poder público porque al parlamento llegan todas las corrientes de opinión y porque en su seno todas estas corrientes son oídas e influyen, tanto en las funciones legislativas como en la fijación de los rumbos generales de la administración pública"; mientras que el régimen presidencial podía "llevar al país rápidamente al absolutismo". Todo ello sin perjuicio de que también reconocieran los vicios del parlamentarismo y estuvieran dispuestos a corregirlos ${ }^{87}$.

Para la prensa conservadora, bastaba dar una mirada a Europa para darse cuenta que "en todas las naciones que han surgido durante la post-guerra, casi la unanimidad de los pareceres ha sido a favor del régimen parlamentario" ${ }^{88}$. La Unión de Valparaíso, que databa el inicio del gobierno parlamentario en nuestro país a mediados del siglo XIX, consideraba que "el parlamentarismo en Chile en sus setenta años de funcionamiento, no ha hecho sino ganar adeptos. Hay quejas contra sus abusos; más no contra su existencia” ${ }^{89}$.

La esencia del régimen parlamentario cuya existencia defendía el Partido Conservador, "llamado también de gabinete" es que tenía "a este a su cabeza, y con plena responsabilidad política. Sin Gabinete responsable ante el Parlamento, no puede existir régimen parlamentario". A los ministros los podía nombrar y remover el Presidente de la República, "pero en tal nombramiento y revocación debe proceder siguiendo los rumbos de la mayoría parlamentaria", porque "lo esencial del régimen parlamentario es la responsabilidad política, que tiene por sanción dejar el puesto, para entregarlo a otro Gabinete, que marche de acuerdo con los rumbos políticos de la mayoría parlamentaria" ${ }^{\circ 0}$. Eso sería de la esencia, "del sistema de gobierno inglés, que fue siempre nuestro modelo" ${ }^{11}$. Al contrario, concluía, la gran "desventaja del régimen presidencial es una menor flexibilidad para seguir los cambios de la opinión pública"92. Incluso se llegaba a aducir que el gobierno parlamentario resultaba más barato que el presidencial ${ }^{93}$.

Se criticaba por los conservadores el que el modelo presidencial que se consideraba por quienes propiciaban el cambio de régimen de gobierno, era el de los Estados Unidos, el que no sería aplicable a las circunstancias de Chile, porque en Norteamérica servía de freno a los poderes presidenciales el régimen federal, mientras que Chile era un país unitario. "El

87 Actas (1925) pp. 410s. Cfr. Diario Ilustrado (9/5/1925) p. 3.

88 Diario Ilustrado (22/8/1925) p. 3.

89 La Unión (19/4/1925) p. 7.

90 Diario Ilustrado (4/5/1925) p. 3.

91 Diario Ilustrado (23/6/1925) p. 3.

92 Diario Ilustrado (20/4/1925) P. 3.

93 La Unión (22/4/1925) p. 3. 
gobierno presidencial entre nosotros, sin la limitación enorme que significa la organización federal, crearía una verdadera dictadura de los presidentes. Sería un gobierno prácticamente irresponsable" 94 .

Para los conservadores el régimen "sui generis, criollo" que pretendía imponer Alessandri, era "singular e inaudito: es la autocracia presidencial con una Cámara consultiva: el absolutismo del Zar de Rusia (...) Esta concepción del poder absoluto ¿es militar o soviética? Parece inútil la respuesta. La democracia no puede aceptar un tiro de gracia, aunque lo dispare su ídolo" 95 .

En la crítica del conservantismo a las reformas propiciadas por Alessandri y los militares solo se manifestaba una cierta discrepancia en cuanto hubo algún sector del partido, de tendencia tradicionalista cristiana, que entendía había llegado el momento para concretar un cambio trascendental en materia de sistema de representación. Para ese sector la discusión en torno a los regímenes de gobierno no dejaba de ser algo superficial, pues la cuestión de fondo era que "mientras se considere a la nación como un conjunto de hombres desligados y abstractos y se eleccione (sic) y legisle y gobierne sobre esa base, los resultados serán pésimos. Se habrá cimentado el edificio sobre unos cimientos inexistentes (...) Las naciones son seres organizados, a base de células vivas y de órganos"96. En opinión del editorialista de La Unión, tanto el presidencialismo como el parlamentarismo debían considerarse como fracasados. "Lo fracasado es el sufragio inorgánico y el Congreso, cuyos diputados no representan ni deben responder ante grupos vivos de electores bien definidos (...) De ahí la necesidad de los verdaderos patriotas de ir preparando pacienzudamente el terreno para una evolutiva y prudente sustitución del régimen actual, invento de los sectores del siglo XVIII, que inventaban esa fantasía del hombre abstracto y articulaba sistemas de espaldas a la realidad"97. Se apuntaba así a una fórmula que dejara de lado el sufragio universal y el sistema de partidos, los que deberían ser reemplazados por un sistema de representación gremial ${ }^{98}$. Por lo demás una posición semejante todavía sería defendida en el seno mismo de la Convención General del Partido celebrada en Valparaíso a mediados de junio de 1925 por el delegado José Luis Sepúlveda, quien presentaría el siguiente voto que no fue aprobado: "El P.C. rechaza la constitución individualista de la sociedad y aspira a su constitución orgánica y, por consiguiente, propenderá: en lo económico a la cooperación de patrones y obreros, y en lo político, a la representación corporativa" ${ }^{\prime 9}$.

Naturalmente una alternativa semejante -el reemplazo de los partidos por los gremios- no la podía aceptar la dirigencia conservadora, porque hubiera significado un negar-

\footnotetext{
94 Diario Ilustrado (21/4/1925) p. 3.

95 La Unión (15/5/1925) p. 3. Los adjetivos utilizados no están tan lejos de los que emplearía al año siguiente el gran jurista austríaco Hans Kelsen, Kelsen (1926), donde señalaba que la Constitución de 1925 contenía una serie de disposiciones que la acercaban a ese tipo de gobierno que hoy día se conoce como dictadura.

96 La Unión $(23 / 4 / 1925)$ p. 3.

97 La Unión $(2 / 6 / 1925)$ p. 3.

98 La Unión (15/5/1925) p. 3.

99 La Unión (14/6/1925) p. 1.
} 
se a sí mismos, por lo que defenderían con firmeza el sistema de partidos ${ }^{100}$. Con particular decisión explicitaría su postura al respecto Arturo Lyon Peña, presidente del Partido Conservador, en un discurso pronunciado ante la Asamblea Provincial conservadora de Concepción, donde señaló que "la teoría de la representación gremial es imposible" y que los partidos políticos "han sido siempre a través de los siglos la única forma descubierta por los hombres para expresar su voluntad en el manejo de los negocios públicos" ${ }^{101}$.

La posición del Partido Conservador frente a la cuestión constitucional quedaría fijada sobre todo en la Gran Convención celebrada en Valparaíso en agosto de 1925. Entre las normas que deberían incorporarse al nuevo texto constitucional, en relación con el funcionamiento del régimen de gobierno, según el documento allí elaborado, se incluían la "independencia del Poder electoral respecto del Ejecutivo. Inscripción y depuración permanente de los registros. Afianzamiento de la libertad electoral"; el "mantenimiento del sistema de Congreso bicameral, pudiendo limitarse las facultades políticas del Senado"; también el "mantenimiento del régimen parlamentario, sin perjuicio de aquellas reformas que aseguren su mejor funcionamiento"; "ampliación de los períodos legislativos de senadores y diputados a cuatro y ocho años respectivamente"; frente al problema de la dieta, se proponía ahora la "remuneración de las funciones legislativas siempre que no pueda ser aumentada por un Congreso en favor de sí mismo sino de los Congresos futuros" ${ }^{102}$; "calificación de las elecciones por un tribunal independiente"; en una cuestión más contingente y dirigida contra la intervención militar exigía "el sometimiento de todos los decretos leyes a la revisión del futuro Congreso, debiendo ser considerados por él, como simples proposiciones de leyes"; "ampliación a seis años del período presidencial"; en una diferencia radical con la proposición de Alessandri -elección directa, que parecía sinónimo de dictadura-, propugnaba la "elección presidencial por el Congreso", lo que habría sido tomado del modelo francés ${ }^{103}$; en el plano del gobierno local, propiciaba la "restauración integral de la comuna autónoma”, obra del prócer conservador Manuel José Yrarrázaval, medio que parecía el más adecuada para hacer realidad la descentralización administrativa; para hacer imposible una nueva intervención militar, debían establecerse "disposiciones eficaces para garantir el alejamiento absoluto de las instituciones armadas de toda acción política”; y por último, proponían mantener el sistema de intervención de dos congresos sucesivos en el procedimiento para reformar la constitución ${ }^{104}$.

La prensa conservadora, por su parte, criticaba el excesivo poder presidencial en materia presupuestaria; en el fondo, el que se pusiera fin a las leyes periódicas que había sido la palanca clave para sostener el régimen parlamentario desde las décadas finales del siglo

\footnotetext{
100 Por lo demás lo harían no solo para enfrentar las propuestas corporativas, sino también los ataques a los partidos que provenían del mismo gobierno, de Alessandri y los militares, Diario Ilustrado (12/8/1925) p. 9.

101 Diario Ilustrado (21/7/1925) p. 11.

102 Los conservadores eran más bien contrarios a la misma o, por lo menos, consideraban que esta debía reducirse a un mínimo. "El salario de un buen obrero especializado debería ser el máximum de la dieta". DiARIO ILUSTRADO (20/7/1925) p. 3.

103 Diario Ilustrado (5/6/1925) p. 9.

104 La Unión (13/6/1925) p. 3.
} 
$\mathrm{XIX}^{105}$. También la incompatibilidad absoluta planteada en el proyecto de Alessandri entre los cargos de Ministros de Estado y los parlamentarios ${ }^{106}$. Se cuestionaba con razones de peso el sistema contemplado de responsabilidad penal -y no política- de los ministros, a través del juicio político, institución que en la práctica, dando razón a los conservadores, se mostraría, en general, ineficiente ${ }^{107}$. "Las acusaciones no reemplazan la influencia del Parlamento en la suerte de los Gabinetes - aunque se faciliten las acusaciones, lo que traerá más inconvenientes que ventajas. El sistema criollo ultrapresidencial, a pesar de las acusaciones fáciles, no puede satisfacer a los partidarios del régimen parlamentario"108.

En materia de garantías individuales se exigía el reconocimiento de la "libertad universitaria", de "la libertad de prensa, sin censura previa"109 y se criticaba con fuerza la regulación que se daba al derecho de asociación en el proyecto del gobierno ${ }^{110}$. Según Rafael L. Gumucio, este "mata la libertad de asociación que conquistó Cifuentes, del mismo modo que mata la autonomía comunal que conquistó Irarrázaval"111.

Pero quizá si el aspecto más significativo de la posición conservadora en materia de garantías individuales, sobre todo en el contexto revolucionario que se vivía en el país y a las tendencias en contrario que se estaban imponiendo en países que siempre habían servido de modelo a los chilenos ${ }^{112}$, fue su defensa irrestricta del derecho de propiedad privada. En el memorándum de reformas constitucionales, aprobado en la convención de Valparaíso de junio de 1925, había dos puntos referidos a ese tema. En el III se aceptaba "la progresividad de los impuestos globales, estableciéndose por vía constitucional un máximo que impida la fijación de tarifas que puedan significar una confiscación o que desalienten el espíritu de ahorro que es la mejor base del bienestar futuro del obrero"; mientras que en el IV se exigía el "mantenimiento integral del $N^{\circ} 5$ del artículo 10 de la Constitución de 1833, referente al derecho de propiedad" 113 .

Esa había sido también la posición sostenida por los miembros del Partido Conservador que integraban la Subcomisión de Reformas Constitucionales, frente a la opinión mayoritaria que pretendía limitar el ejercicio del derecho de propiedad, tomando para ello argumentos tanto de la Constitución alemana de Weimar de 1919 (art. 153), como de la

\footnotetext{
105 Constitución de 1833, art. $44 \mathrm{~N}^{\circ} 4$.

106 Diario Ilustrado (7/5/1925) p. 9. Constitución de 1833, arts. 28ss.

107 Diario Ilustrado (14/5/1925) p. 3 "Contra control del Presidente por la vía de la acusación constitucional”, y (4/8/1925) p. 3. Cfr. Bravo Lira (1978). ConstituCión de 1833, arts. $391^{\text {a }}$ y $421^{\text {a }}$.

108 Diario Ilustrado (11/8/1925) p. 3.

109 La Unión (13/6/1925) p. 3.

110 Constitución de 1833, Art. 12 N 5: "El derecho de asociación sin permiso previo y en conformidad a la ley".

111 Diario Ilustrado (4/8/1925) p. 3.

112 BRAHM (1999).

113 LA UNIÓN (14/6/1925) p. 5. En su versión original se trataba del 12, pero una reforma constitucional de 1888 derogó los artículos 1 y 9. En él se garantizaba "la inviolabilidad de todas las propiedades, sin distinción de las que pertenezcan a particulares o comunidades, y sin que nadie pueda ser privado de la de su dominio, ni de una parte de ella por pequeña que sea, o del derecho que a ella tuviere, sino en virtud de sentencia judicial..."
} 
doctrina de la función social de la propiedad de León Duguit ${ }^{114}$. Por ejemplo, si bien aceptaban que se diera rango constitucional a la progresividad de los impuestos, planteaban sus temores, ante el "peligro o la amenaza que significaría para la capitalización y el ahorro un impuesto progresivo", planteando la posibilidad de que se pudiera "fijar alguna formalidad o quorum para establecer la progresión cuando suba cierta escala, a fin de evitar que la contribución se convierta en la práctica en una amenaza contra el derecho de propiedad, contra el ahorro y contra la capitalización" ${ }^{115}$.

Por otra parte, al defender la mantención del texto íntegro del $\mathrm{N}^{\circ} 5$ del artículo 10 de la Constitución de 1833, Romualdo Silva Cortés expresaba que "no se trata de lo que se llama una función social; sino de un derecho natural. Se trata de una prolongación de la personalidad humana (...) El derecho de propiedad existió antes de la formación de los Estados. Se trata de algo que el hombre necesita poseer con derecho estable y que dure, para el alivio y bienestar y la satisfacción de necesidades del individuo y de la familia"116. Todo ello sin perjuicio de aceptar que en otro artículo distinto del proyecto de reforma constitucional, "se considerase el fomento del bienestar de los obreros y los deberes de justicia y de caridad para con los pobres". Según Silva Cortés, "el uso cristiano de las riquezas es un factor necesario en la vida de la sociedad. Existen deberes sociales que un legislador, y con mayor razón un constituyente, necesitan considerar, pero ésta es una cuestión distinta y separada de la cuestión de inviolabilidad del derecho de dominio" ${ }^{117}$.

Era esta también la postura del Diario Ilustrado cuando, por ejemplo, insistía en la necesidad de mantener "el pago real de indemnización en casos de expropiación", o criticaba la norma propuesta por la que se buscaba el estado propendiera a "la división de la propiedad y a la constitución de la propiedad familiar"118. Según el editorialista, "el verbo "propender", en realidad no compromete a mucho. Pero se deja lugar a interpretaciones inconvenientes. La división de la propiedad se verifica espontánea, económicamente"119.

Sin perjuicio de lo anterior, es posible también encontrar alguna posición discrepante -que demuestra que el Partido Conservador estaba lejos de ser monolítico en lo doctrinario- que no estaba de acuerdo con la postura oficial. Contestando una crítica formulada por El Mercurio en estas materias, La Unión de Valparaíso respondía señalando que "la escuela individualista, manchesteriana, tal como la entienden los editorialistas de la prensa liberal no puede hallarse encarnada en el P. Conservador Católico, cuya divisa de acción fundamental ostenta la defensa del orden social cristiano"; se trata de un partido "que tiene por punto de honra y hasta por precisa condición de vida, atenerse a las enseñanzas de los

\footnotetext{
114 Brahm (2012) pp. 239ss. Cfr. Además, Brahm (1986) y Brahm (1992).

115 ACTAS (1926) p. 84.

116 ACTAS (1926) p. 88.

117 ACTAS (1926) p. 89. Lo que molestaba a Silva Cortés y a otros conservadores, era el tenor literal del inc. $3^{\circ}$ del art. $10 \mathrm{~N}^{\circ} 10$, donde se señalaba: "El ejercicio del derecho de propiedad está sometido a las limitaciones o reglas que exijan el mantenimiento y progreso del orden social, y, en tal sentido, podrá la ley imponerle obligaciones o servidumbres de utilidad pública en favor de los intereses generales del Estado, de la salud de los ciudadanos y de la salubridad pública".

118 Constitución de 1925 , art. $10 \mathrm{~N}^{\circ} 14$ inc. $2^{\circ}$

119 Diario Ilustrado (22/5/1925) p. 3.
} 
Papas" ${ }^{120}$. Más todavía, y mientras tenía lugar la Convención del partido donde se discutían estos temas, la misma Unión publicaba un artículo titulado "El derecho de propiedad según la doctrina católica”, con citas tomadas de diversas fuentes. En una de ellas se señalaba: "Para el liberalismo la propiedad me da derecho absoluto. El Cristianismo desde hace siglos ha refutado semejante error. Para el Cristianismo, la propiedad tiene una función social esencial. Concebir la propiedad como un derecho absoluto es pisotear la doctrina cristiana sobre la propiedad. Todos los Santos Padres están de acuerdo sobre este punto"121.

Plena unanimidad habría en cambio entre los conservadores en la defensa del principio de la unión de la Iglesia y el Estado, que había sido un elemento central de la institucionalidad chilena desde la ápoca indiana, y con el que Alessandri quería terminar ${ }^{122}$. Citando palabras del arzobispo de Santiago, el Diario Ilustrado sostenía que dicha separación "significa negación pública y solemne de Dios, verdadera y terrible apostasía nacional" 123. Mientras que en el seno de la Comisión Consultiva de reformas constitucionales, el presidente del Partido Conservador señalaba que "nuestros principios religiosos (...) no nos permiten aceptar la separación de la Iglesia del Estado, ni la supresión de las fórmulas cristianas que se refieren a Dios, a los Evangelios y a la Iglesia, contenidos en la Constitución Política de la República promulgada en 1833 "124.

Finalmente los conservadores resultarían derrotados. El día 30 de agosto de 1925 el proyecto de constitución que recogía el modelo presidencial defendido por Alessandri y los militares resultaría aprobado en un plebiscito en el que votaron menos de la mitad de los ciudadanos inscritos ${ }^{125}$. En todo caso seguirían defendiendo el modelo parlamentario en los años siguientes, con particular fuerza durante el gobierno de Emiliano Figueroa ${ }^{126}$.

\section{CONCLUSIÓN}

En medio de la crisis constitucional que vivía Chile el año 1925, el Partido Conservador se irguió como uno de los grandes defensores de la vigente Constitución de 1833 y de la interpretación parlamentaria de la misma que se había impuesto tras la Guerra Civil de 1891. Con gran valentía y decisión, enfrentando el clima revolucionario ambiente y el autoritarismo del gobierno de Alessandri, que se sostenía en el apoyo militar, el partido y, sobre todo, la prensa conservadora, se opondrían a la idea de convocar a una asamblea constituyente, al plebiscito con el que se terminaría de aprobar la Constitución de 1925 y al régimen presidencial que esta regulaba.

\footnotetext{
120 La Unión (13/6/1925) p. 3.

121 LA UNIÓN (14/6/1925) p. 3.

122 Diario Ilustrado (9/3/1925) P. 5, (20/4/1925) p. 11 y (26/6/1925) p. 3 y La Unión (26/6/1925) p. 11. Sobre la separación de la Iglesia y el estado puede consultarse PACHeCo et al. (2004) y TAgle (1997). ConstituCIÓN DE 1833 , art. 5.

123 Diario Ilustrado (26/6/1925) p. 11.

124 Actas (1926) p. 402. Cfr. Actas (1929) pp. 302 y 397. Cfr. También La Unión (13/7/1925) p. 1 y de

(25/6/1925) p. 3. La Unión (16/7/1925) P. 3 publicó también un artículo del profesor José María Cifuentes).

125 Vial (1986) p. 548.

126 Donoso (1976) y Brahm, Bertelsen y Amunátegui (2002) pp. 33ss.
} 
Pero resulta evidente que, por debajo de esas cuestiones en las que los conservadores actuaban de forma unitaria, el ambiente revolucionario dominante había permeado también las filas del partido. En efecto, dentro de él se podían encontrar ahora sectores que exigían su democratización, esto es, que la aristocracia diera más espacio en la conducción del mismo a representantes de las provincias, a los sectores medios, a la juventud y a los obreros; que tomara forma la "democracia cristiana". También había quienes querían se diera más protagonismo a la doctrina social de la Iglesia en el programa partidario, por ejemplo en materia de derecho de propiedad. E, incluso, estaban aquellos, con particular fuerza en Valparaíso y que tenían como medio de expresión al Diario La Unión, que inspirados en documentos papales y en doctrinas propias del tradicionalismo cristiano, eran partidarios de un régimen corporativo. Hacia el año 1925 ya estaba en ciernes el movimiento que terminaría por provocar la división del Partido Conservador en las décadas siguientes.

\section{BIBLIOGRAFÍA CITADA}

Ahumada, Arturo (1931): El Ejército y la revolución del 5 de septiembre de 1924 (Santiago, Imprenta La Tracción).

Alessandri, Arturo (1967): Recuerdos de gobierno (Santiago, Nascimento).

Arancibia Clavel, Patricia (ed.) (2007): El Ejército de los chilenos 1540 - 1920 (Santiago, Editorial Biblioteca Americana).

Brahm García, Enrique (1986): "El derecho de propiedad en el nacionalsocialismo alemán”, Revista Chilena de Derecho, vol. 13 n³: pp. 441-452.

Brahm García, Enrique (1992): "La propietarización de los derechos en la Alemania de entre guerras", Revista Chilena de Derecho; vol. 19 n³: pp. 411-414.

Brahm García, Enrique (1999): Propiedad sin libertad: Chile 1925-1973. Aspectos relevantes en los avances de la legislación socializadora (Santiago, Ediciones de la Universidad de los Andes).

Brahm García, Enrique (2003): Preparados para la guerra. Pensamiento militar chileno bajo influencia alemana 1885-1930 (Santiago, Ediciones Universidad Católica de Chile).

Brahm García, Enrique (2005): "La elección presidencial de 1925: el candidato equivocado”, en San Francisco, Alejandro y Soto, Ángel (edits.) (Santiago, Centro de Estudios Bicentenario): pp. 39-80.

Brahm García, Enrique (2007): Mariano Egaña: Derecho y política en la fundación de la república conservadora (Santiago, Centro de Estudios Bicentenario).

Brahm García, Enrique (2012): “Algunos aspectos del proceso de socialización del derecho de propiedad en Chile durante el gobierno del general Carlos Ibáñez del Campo (19271931)", Rechtsgeschichte. Legal History, N 20: pp. 234-256.

Brahm García, Enrique, Bertelsen Repetto, Raúl, Amunátegui Echeverría, Andrés (2002): Régimen de gobierno en Chile. ¿Presidencialismo o parlamentarismo? 1925-1973 (Santiago, Editorial Jurídica de Chile).

BRAVO LiRA, Bernardino (1986): Régimen de gobierno y partidos politicos en Chile 1924-1973 (Santiago, Editorial Jurídica de Chile). 
Collier, Simon y SATer, William (1998): Historia de Chile 1808-1994 (España, Cambrigde University Press).

Correa, Sofía (2004): Con las riendas del poder. La derecha chilena en el siglo XX (Santiago, Editorial Sudamericana).

Cristi, Renato y RuIz, Carlos (1992): El pensamiento conservador en Chile (Santiago, Editorial Universitaria).

Donoso, Crescente (1976): "Notas sobre el origen, acatamiento y desgaste del régimen presidencial, 1925-1973", Historia, $\mathrm{N}^{\circ}$ 13: pp. 271-352.

Donoso Zañartu, María Cecilia (1980): Crisis del régimen parlamentario en Chile (Valparaíso, Memoria para optar al grado de Licenciado en Ciencias Jurídicas y Sociales de la Universidad Católica de Valparaíso).

EIchenhofer, Eberhard (2007) Geschichte des Sozialstaats in Europa (München, C.H. Beck).

Escobar, Dina e Iluvic, Jorge (1984): "Documentos. El manifiesto del 11 de septiembre de 1924”, Dimensión Histórica de Chile, N 1: pp. 130-139.

GaLl, Lothar (1978): "Zum Ausbildung und Charakter des Interventionsstaates", Historische Zeitschrift 227: pp. 552-570.

Góngora, Mario (1981): Ensayo histórico sobre la noción de Estado en Chile en los siglos XIX y XX (Santiago, Editorial La Ciudad).

Kelsen, Hans (1926): "Bemerkungen zur chilenischen Verfassung", Zeitschrift für öffentliches Recht 5: pp. 616-619.

Ministerio del Interior (1926): Actas oficiales de las Sesiones celebradas por la Comisión y Subcomisiones encargadas del estudio del Proyecto de Nueva Constitución Política de la República (Santiago, Imprenta Universitaria).

Pacheco, Máximo, Muñoz, Jaime y García-Huidobro, Cristóbal (2004) La separación de la Iglesia y el Estado en Chile y la diplomacia vaticana (Santiago, Editorial Andrés Bello).

Pereira, Teresa (1994): El Partido Conservador 1930-1965. Ideas, figuras y actitudes (Santiago, Fundación Mario Góngora).

Schivelbusch, Wofgang (2008): Entfernte Verwandschaft. Faschismus, Nationalismus, New Deal 1933-1999 (Frankfurt/M., Fischer).

Scotт, Harry (2009): Pensando el Chile Nuevo. Las ideas de la revolución de los tenientes y el primer gobierno de Ibáñez, 1924-1931 (Santiago, Centro de Estudios Bicentenario).

STOLLEIS, Michael (1999): Geschichte des öffentlichen Rechts in Deutschland, Bd. III, (München, C. H. Beck).

Millar, René (1972-1973): "Significado y antecedentes del movimiento militar de 1924", Historia, $\mathrm{N}^{\circ}$ 11: pp. 7-102.

Millar, RenÉ (1981): La elección presidencial de 1920 (Santiago, Editorial Universitaria).

Monreal, Enrique (1929): Historia documentada del periodo revolucionario, 1924-1925 (Santiago, s.n.).

Rodríguez Mendoza, Emilio (1938): El golpe de estado de 1924. Ambiente y actores (Santiago, Ercilla).

SÁEz, Carlos (1933): Recuerdos de un soldado. El Ejército y la política (Santiago, Biblioteca Ercilla). 
TAgle, Matías (1997): "La separación de la Iglesia y el estado en Chile. Historiografía y debate", Historia, vol. 30: pp. 383-439.

VIAL, Gonzalo (1986): Historia de Chile (1891-1973), vol. III, Arturo Alessandri y los golpes militares (1920-1925) (Santiago, Santillana).

\section{PRENSA CITADA}

El Diario Ilustrado marzo a agosto de 1925.

La Unión de Valparaíso marzo a agosto de 1925.

\section{NORMAS CITADAS}

Constitución Política de 1833.

Constitución Política de 1925. 
